Check for updates

Cite this: RSC Adv., 2018, 8, 41499

\title{
The soil chemical properties of reclaimed land in an arid grassland dump in an opencast mining area in China
}

\begin{abstract}
Yuhan Huang, (D) Xinyu Kuang, ${ }^{a}$ Yingui Cao*ab and Zhongke Bai ${ }^{\text {ab }}$
Opencast coal mining damages the land in arid grassland mining areas where topsoil is scarce. Restoration of the soil chemical properties is important for land reclamation and the rebuilding of vegetation. We studied a south dump after 4 years of reclamation, a north dump after 8 years of reclamation, and undamaged land to identify changes in the soil profile after mining and reclamation. Variance, correlation, and principal component analyses assessed spatial and temporal differences, and correlations between soil organic matter (SOM), total nitrogen (STN), available phosphorus (SAP), available potassium (SAK), and soil $\mathrm{pH}(\mathrm{pH})$ in the $0-40 \mathrm{~cm}$ layers. The soil chemical properties were evaluated to support the reconstructed soil profiles and guide soil reconstruction in grassland mining areas. SOM, STN, SAP, and SAK in the south dump were significantly lower than those in the undamaged land. SOM and STN levels in the north dump were lower than those in the undamaged land. SAP and SAK levels in the north dump were higher than those in the undamaged land. Therefore, land reclamation can improve the chemical properties of the reconstructed soil profile in grassland mining areas lacking SAP. Principal component analysis revealed that increasing reclamation years improved the soil chemical quality, and that of the surface soil was better than that of the lower layer. The chemical quality of the soil below $20 \mathrm{~cm}$ was consistent. At $0-40 \mathrm{~cm}$, correlations between the soil chemical properties declined from top to bottom, and changed from interdependent to mutually independent; SOM was the core element. The use of topsoil and coal gangue to construct soil profiles can improve the soil chemical properties and resolve the difficulties of land reclamation caused by surface soil scarcity and droughts.
\end{abstract}

Received 27th September 2018 Accepted 19th November 2018

DOI: $10.1039 / c 8 r a 08002 j$

rsc.li/rsc-advances

\section{Introduction}

China is a large coal mining country, and since the foundation of the People's Republic of China, coal has accounted for approximately $70 \%$ of disposable energy consumption. The proportion of opencast coal mining in the total output has increased to $30 \%,{ }^{\mathbf{1 , 2}}$ therefore coal resources are an important material basis for national economic and social development., However, land damage caused by opencast mining restricts the sustainable development of mining areas., ${ }^{5,6}$ China's large opencast coal mines are mostly distributed in ecologically fragile areas. ${ }^{2,7}$ With the construction and production of opencast mines, dumps occupy a large amount of land and destroy the soil structure, resulting in soil nutrient loss, which affects vegetation growth and ultimately destroys the original landform and ecological environment. ${ }^{\mathbf{8} 9}$ Therefore, research on

${ }^{a}$ School of Land Science and Technology, China University of Geosciences, Beijing 100083, China. E-mail: caoyingui1982@126.com

${ }^{b}$ Key Lab of Land Consolidation, Ministry of Land and Resources of the PRC, Beijing 100035, China reconstructed soil quality in the land reclamation of dumps has attracted much attention.

It is key to improve reclamation technology and quality by comparing the chemical status of reconstructed soil from different reclamation years. The Land Reclamation Quality Control Standards in China (TD/T 1036-2013) clearly indicate the control range of soil chemical indicators such as SOM and $\mathrm{pH}$ values in reclaimed land. Studies have shown that significantly different chemical properties exist between the soils from reclaimed and undamaged lands from different locations and years. ${ }^{\mathbf{1 0 - 1 4}}$ By analyzing the differentiation and mechanisms of the chemical properties of reconstructed soil, Cao et al. ${ }^{15,16}$ proposed specific measures to optimize the techniques of land reclamation from a microscopic perspective. Farnden et al. ${ }^{13}$ showed that reconstructed soil tends to present lower fertility than natural soil, however improved nutrient status can effectively improve soil quality. ${ }^{17}$ In addition, related studies indicate that reconstructed soil chemical factors are the main factors affecting vegetation distribution. ${ }^{18-20}$ Liu et al. ${ }^{21}$ used one-way ANOVA and fitting analysis to effectively reflect differences and relationships between reconstructed soil chemical properties and NDVI. Therefore, studying the chemical properties of 
reconstructed soil is important for rebuilding vegetation and ecological restoration. ${ }^{11}$ Presently, the study of reconstructed soil chemical properties in China mainly focuses on the Loess Plateau region, and most scholars conduct research based on a single indicator, ignoring the correlations between the soil chemical properties. However, the study of the chemical properties of reconstructed soils in grassland mining areas with very scarce topsoil and an arid climate is rare.

To further enrich the research on soil reconstruction in opencast mining areas, the objectives of this study were to: (1) analyze the differences and correlations between the chemical properties of reconstructed soil, and to study the mechanisms responsible, (2) comprehensively evaluate the chemical properties of reconstructed soil to provide information for soil reconstruction and vegetation rebuilding, and (3) explore the land reclamation modes suitable for grassland mining areas with scarce topsoil and an arid climate.

\section{Materials and methods}

\subsection{Study area}

The Shenhua Beidian Shengli opencast coal mine is located in the eastern part of the Inner Mongolia Plateau, $3 \mathrm{~km}$ north of Xilinhot City, with the geographical coordinates: $115^{\circ} 30^{\prime}-$ $116^{\circ} 26^{\prime} \mathrm{E}, 43^{\circ} 57^{\prime}-44^{\circ} 14^{\prime} \mathrm{N}$. The whole coal field is distributed in the northeast-southwest strip. ${ }^{22}$ The Shengli no. 1 opencast mine is the best ore field in regards to coal seams and coal quality, and it is located in the mid-west part of the coalfield, 6 $\mathrm{km}$ from Xilinhot city, and includes three outdoor dump sites (south dump, north dump, and side-slope dump) (Fig. 1). The surface is $6.84 \mathrm{~km}$ long from east to west, $5.43 \mathrm{~km}$ from north to south, $37.14 \mathrm{~km}^{2}$ in coal area, and 1934.43 Mt in geological reserves. The recoverable geological reserves are 1854.79 Mt, and the average stripping ratio is $2.59 \mathrm{~m}^{3} \mathrm{t}^{-1}$. The project area has a mid-temperate semi-arid continental grassland climate, with strong winds in spring, autumn and winter, and the main form of soil erosion is wind erosion. The average annual temperature is $1.7^{\circ} \mathrm{C}$, the average annual precipitation is 294.74 $\mathrm{mm}$, and the annual average evaporation is $1794.4 \mathrm{~mm} .^{23}$ The study area belongs to the zonal vegetation area type of typical grassland, and the vegetation coverage is $40-75 \%$. The nonzonal soil is mainly meadow soil, and the organic matter content is $2.00-3.68 \%$. The soil nutrient status is generally phosphorus deficient, potassium enriched, and medium in nitrogen, has a $\mathrm{pH}$ of 8 , and has clear calcium accumulation below $20 \mathrm{~cm}$ of the soil surface layer.

\subsection{Soil sampling and determination}

Three typical sites were selected in the Shenhua Beidian Shengli opencast mine in September 2017, which were each built on undamaged land, and on the top platforms of the south and north dumps. The average thicknesses of the soil layers were 20,

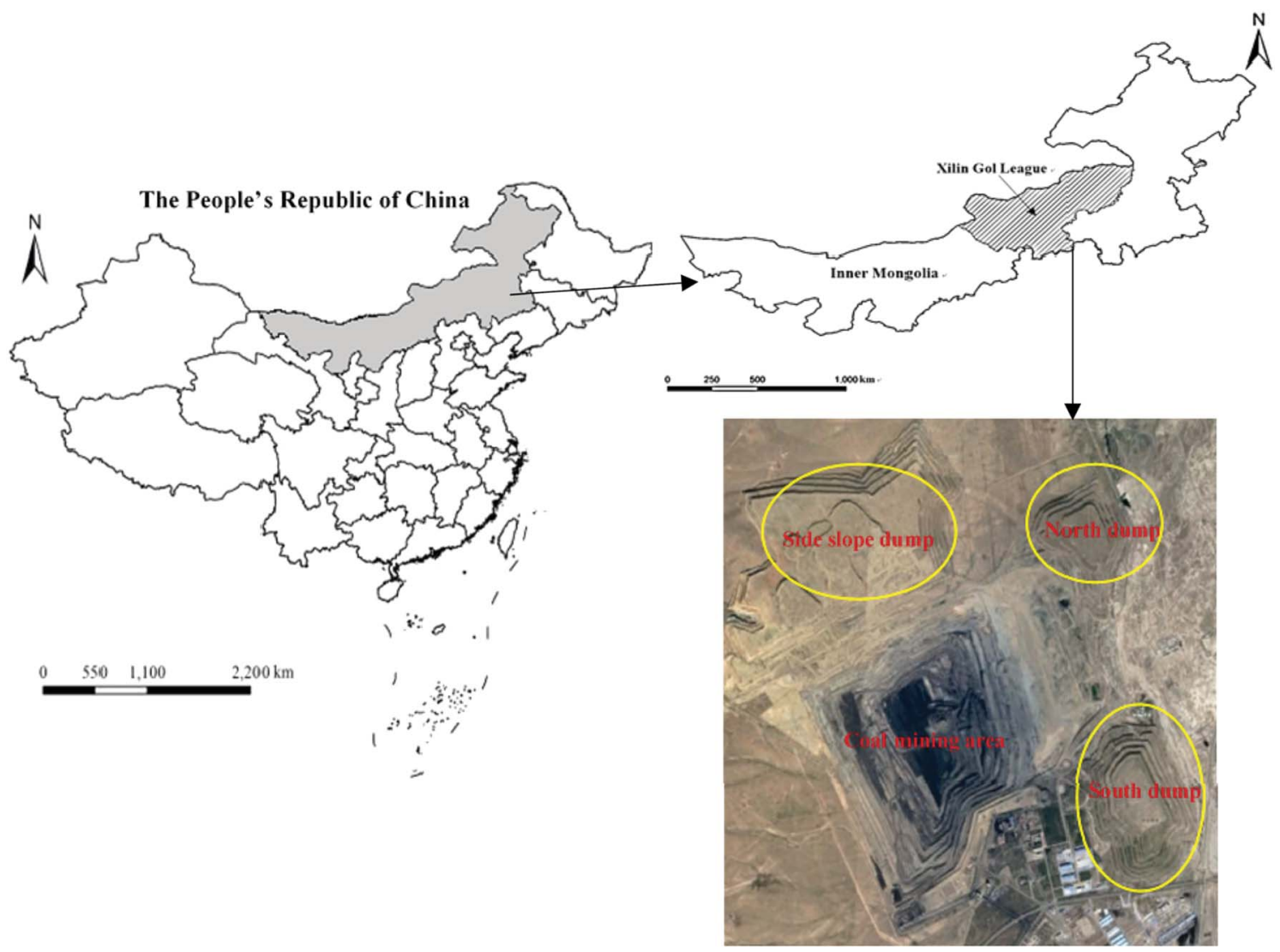

Fig. 1 Location of the no. 1 opencast coal mine in the Shengli mining area. 
Table 1 List of sampling site profiles

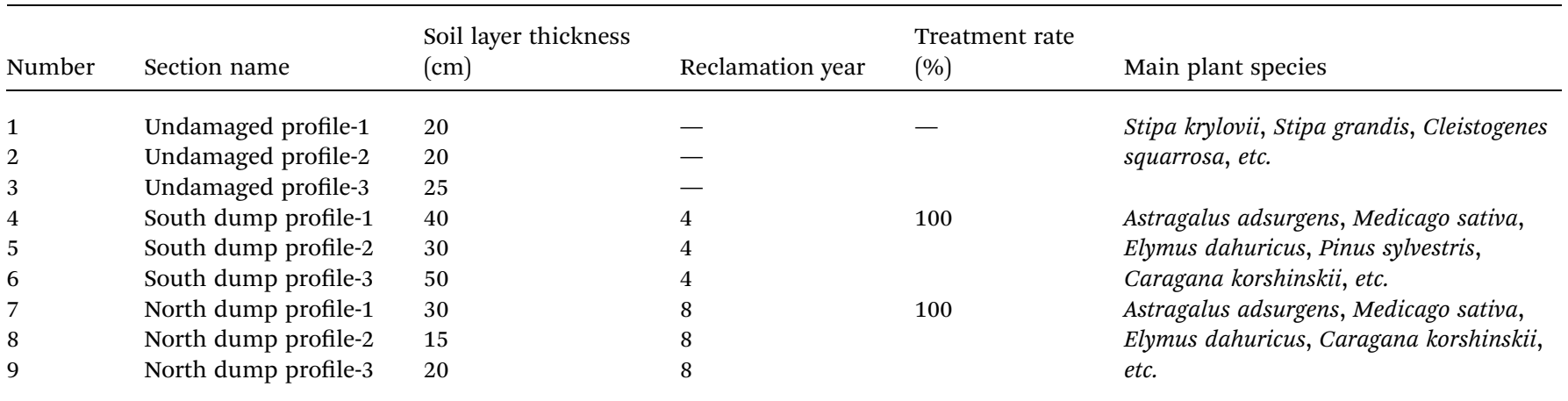

40 , and $20 \mathrm{~cm}$, respectively, and coal gangue was found below the soil layer of the reclaimed land. To study the chemical properties of the reconstructed soil, three soil profiles were excavated randomly from each site; we used a spade to stratify 0-10, 10-20, 20-30, and 30-40 cm soil samples, which were placed into cloth bags. The number, name, soil thickness, reclamation status, and vegetation type of each plot are shown in Table 1.

The soil chemical properties of the test samples were determined via The Beijing Research Center for Agricultural Standards and Testing, where the SOM content was determined by a volumetric method of $\mathrm{K}_{2} \mathrm{Cr}_{2} \mathrm{O}_{7}$ heating using an electric sand bath. The STN content was determined using an automatic nitrogen analyzer, the SAP content was determined by the Olsen method, the SAK content was extracted by a $\mathrm{CH}_{3} \mathrm{COONH}_{4}$ solution and determined by a flame photometer, and the soil $\mathrm{pH}$ value was determined by potentiometry.

\subsection{Data processing}

The data were processed and charted using SPSS 25.0 and Microsoft Excel 2016 software. One-way ANOVA and Pearson correlation analysis were performed on the soil chemical indicators, with statistical significance defined as $a=0.05$, and extreme significance defined as $a=0.01$. In addition, the grading standards for soil nutrient content in this study area were based on The Second National Soil Census Soil Nutrient Grading Standard (Table 2), ${ }^{\mathbf{2 4 - 2 6}}$ and principal component analysis of the multivariate statistical analysis was applied for the comprehensive evaluation of the soil chemical properties.

\section{Results}

\subsection{Differences in the soil chemical properties}

Using reclaimed land from the south and north dumps as the key research objects, the SOM, STN, SAP, SAK, and $\mathrm{pH}$ of the reconstructed soil in the dumps were compared with those from the undamaged land. We used one-way ANOVA to analyze the differences between the chemical properties of reconstructed soil from the reclaimed and undamaged land from overall and vertical perspectives.

Overall, there were significant differences among the indicators $(P<0.05)$, all of which passed the $F$ test. There was a significant difference in SOM between the undamaged land and the south dump; the average SOM content in the undamaged land was higher than that in the reclaimed land, but the standard deviation of the SOM in the undamaged land was lower than those in the reclaimed lands (Fig. 2a). There was a significant difference in the STN between the undamaged and reclaimed lands, while the difference between the reclaimed lands was not significant, and the average content and standard deviation of the STN in the undamaged land were greater than those in the reclaimed lands (Fig. 2b). There were significant differences in SAP and SAK between the reclaimed lands; the differences between the reclaimed and undamaged lands were not significant, and the average SAP and SAK levels in the north dump were higher than those in the undamaged land and the south dump (Fig. 2c and d). There were significant differences in $\mathrm{pH}$ between the south dump, the undamaged land, and the north dump, and the average value and standard deviation of the $\mathrm{pH}$ in the south dump were higher than those in the north

Table 2 Soil nutrient grading standards ${ }^{a}$

\begin{tabular}{|c|c|c|c|c|c|}
\hline Level & Abundance and deficiency & $\begin{array}{l}\mathrm{SOM}(\mathrm{g} \\
\left.\mathrm{kg}^{-1}\right)\end{array}$ & $\operatorname{STN}\left(\mathrm{g} \mathrm{kg}^{-1}\right)$ & $\mathrm{SAP}\left(\mathrm{mg} \mathrm{kg}^{-1}\right)$ & SAK $\left(\mathrm{mg} \mathrm{kg}{ }^{-1}\right)$ \\
\hline 1 & Very rich & $>40$ & $>2.0$ & $>40$ & $>200$ \\
\hline 3 & Medium & $20-30$ & $1.0-1.5$ & $10-20$ & $100-150$ \\
\hline 4 & Lacking & $10-20$ & $0.75-1.0$ & $5-10$ & $50-100$ \\
\hline 5 & Very lacking & $6-10$ & $0.5-0.75$ & $3-5$ & $30-50$ \\
\hline
\end{tabular}

${ }^{a}$ Quoted from The Second National Soil Census Technical Regulations. SOM, soil organic matter; STN, soil total nitrogen; SAP, soil available phosphorus; SAK, soil available potassium. 


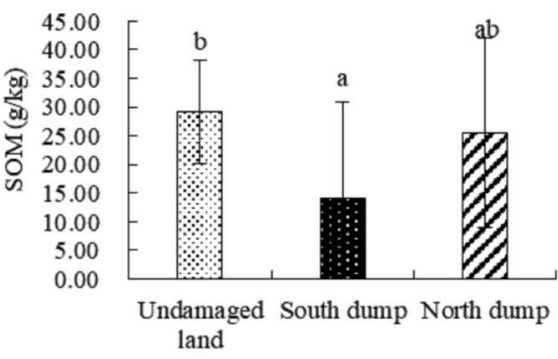

(a)

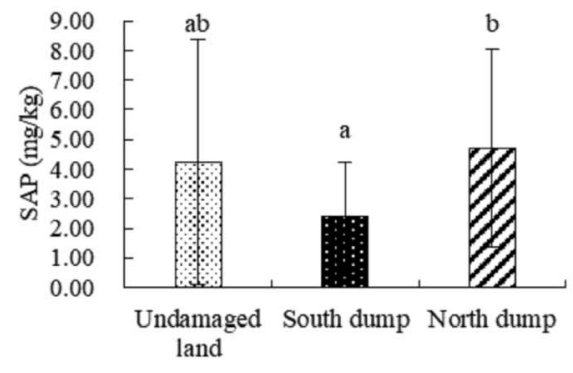

(c)

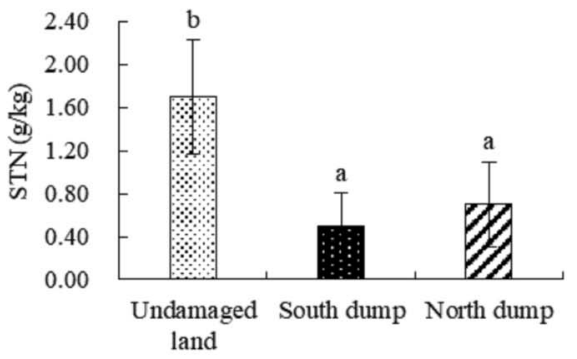

(b)

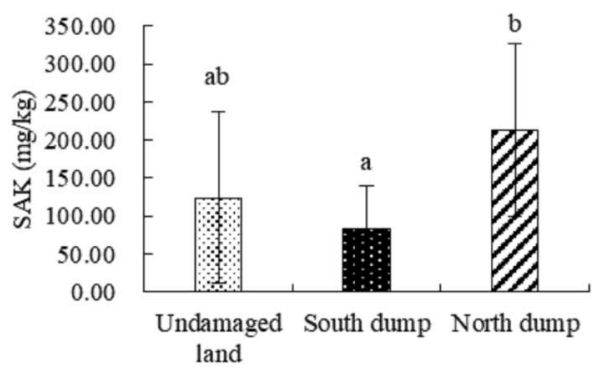

(d)

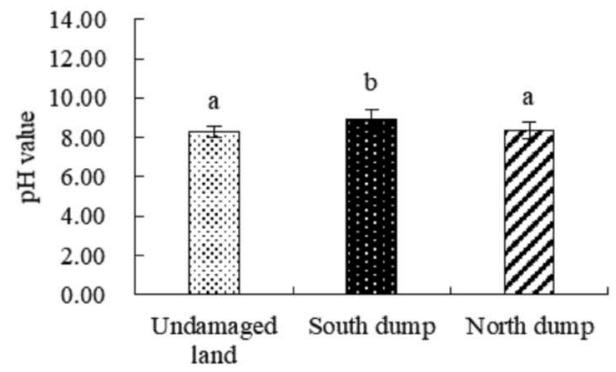

(e)

Fig. 2 Overall differences in the soil chemical properties of the various plots: $a$ and $b$ indicate a significant difference between the two, and ab indicates no significant difference, $P<0.05$.

dump and the undamaged land (Fig. 2e). Overall, the SOM and STN content of the reconstructed soil in the north dump after 8 years of reclamation had not reached the levels observed in the undamaged land, while the SAP and SAK content in the north dump had reached the levels observed in the undamaged land. However, after 4 years of reclamation, there were significant differences in the soil chemical properties between the south dump and the undamaged land.

Based on the soil nutrient grading standards set forth in The Second National Soil Census Technical Regulations (Table 2), the soil nutrient status in the mining area was graded and is shown in Table 3. Comparative analysis revealed that the nutrient levels of SOM and STN in the undamaged land were

Table 3 Soil nutrient grading of the various plots

\begin{tabular}{lllll}
\hline & \multicolumn{2}{l}{ Nutrient grading } \\
\cline { 2 - 5 } Sample plot & SOM & STN & SAP & SAK \\
\hline Undamaged land & 3 & 2 & 5 & 3 \\
South dump & 4 & 5 & 6 & 4 \\
North dump & 3 & 5 & 5 & 1
\end{tabular}

higher than those in the north and south dumps. The nutrient levels of SAP and SAK in the north dump were higher than those in the undamaged land and the south dump. We inferred that the soil nutrient status of the undamaged land and the north dump in the mining area was better than that in the south dump. However, the SAP content in the grassland mining area was generally lacking, and opencast mining activities resulted in a substantial loss of soil nutrients. But after land reclamation, the nutrient status of the reconstructed soil improved as the number of reclamation years increased. Notably, following 8 years of reclamation, the SAK content in the north dump exceeded that in the undamaged land and reached the first level.

In the vertical section, the soil chemical properties of the undamaged and reclaimed land were analyzed by one-way ANOVA (Fig. 3). In the $0-10 \mathrm{~cm}$ soil layer, the SOM and STN levels were significantly different between the undamaged land and the south dump, and the average levels of SOM and STN in the undamaged land were higher than those in the north and south dumps. There was a significant difference in SAK amongst the reclaimed lands, but the differences between the undamaged and reclaimed lands were not significant, and the 


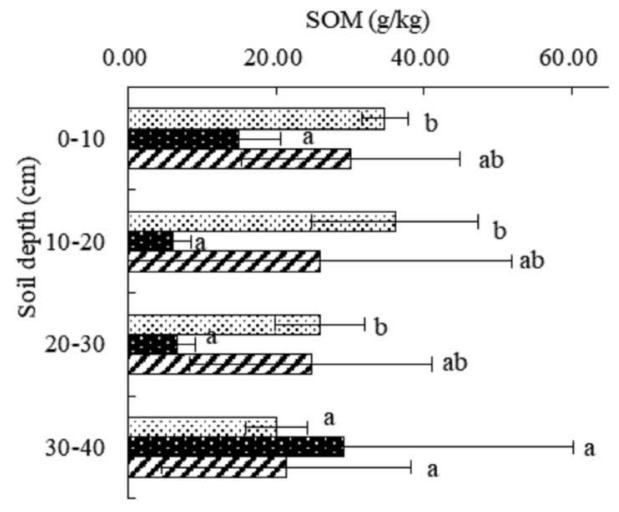

ĐUndamaged land a South dump aNorth dump

(a)

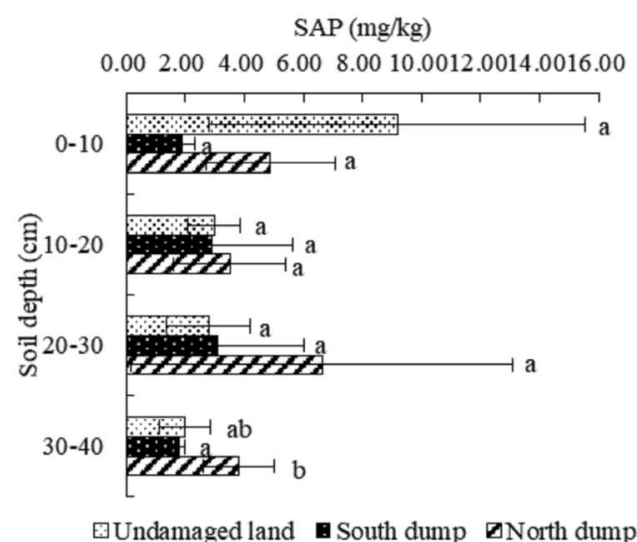

(c)
$\mathrm{STN}(\mathrm{g} / \mathrm{kg})$

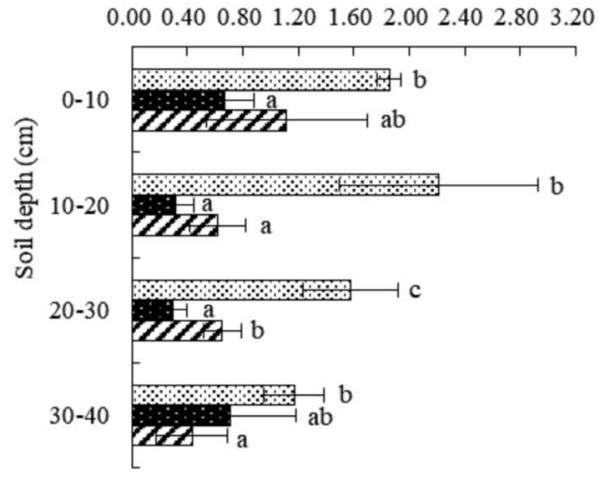

๑Undamaged land $\mathbf{a}$ South dump घNorth dump

(b)

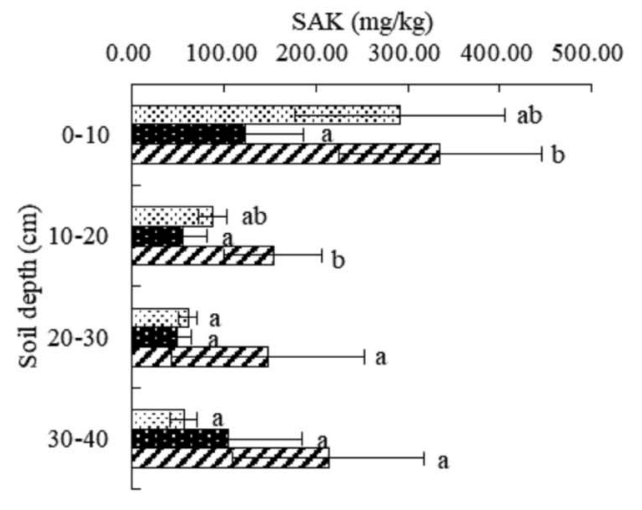

ĐUndamaged land $\mathbf{E}$ South dump $\square$ North dump

(d)

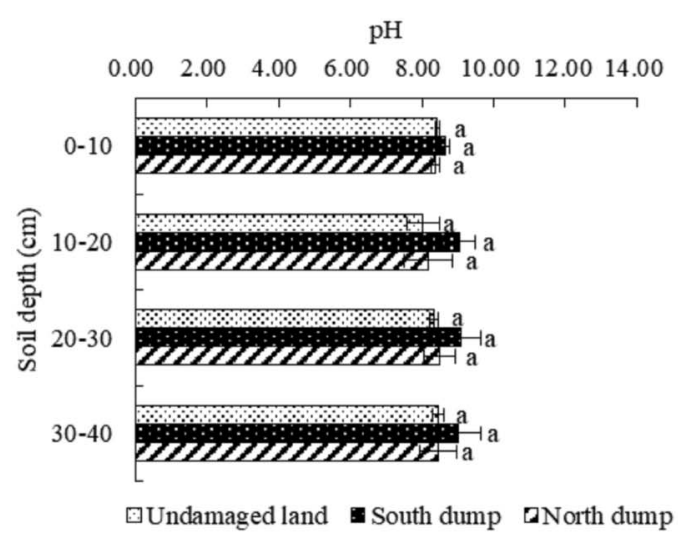

(e)

Fig. 3 Vertical differences in the soil chemical properties of the various plots.

average SAK content in the north dump was higher than that in the undamaged land and the south dump. The differences in SAP and $\mathrm{pH}$ between the reclaimed and undamaged lands were not significant. In the $10-20 \mathrm{~cm}$ soil layer, the differences in the soil chemical properties were not different from those in the 0 $10 \mathrm{~cm}$ layer between the undamaged and reclaimed lands; however the STN content between the north and south dumps was significantly different at a depth of 10-20 cm. In the $20-$
$30 \mathrm{~cm}$ soil layer, the difference in SOM between the undamaged and reclaimed lands was consistent with that in the $0-20 \mathrm{~cm}$ layer. There was a significant difference in STN between the undamaged land and the south and north dumps; the average STN content in the undamaged land was higher than that in the north and south dumps. The differences in SAP, SAK and $\mathrm{pH}$ between the reclaimed and undamaged lands were not significant. In the 30-40 cm soil layer, there were no significant 
differences in SOM, SAK, and $\mathrm{pH}$ between the reclaimed and undamaged lands. There was a significant difference in STN between the undamaged land and the north dump, and the average STN content in the undamaged land was higher than that in the south and north dumps. There was a significant difference in SAP among the reclaimed lands; however, the differences between the undamaged and reclaimed lands were not significant, and the average SAP content in the north dump was higher than that in the undamaged land and the south dump.

The differences in the soil chemical properties between the reclaimed and undamaged lands at $0-10 \mathrm{~cm}$ were consistent with those at 10-20 cm, while the differences in the soil chemical properties between the reclaimed and undamaged lands at $20-40 \mathrm{~cm}$ differed from those at $0-20 \mathrm{~cm}$. This may be associated with the configuration of the soil profile; the heterogeneity of the reconstructed soil profile configuration may have led to differences in its chemical properties, compared with those of the undamaged land.

\subsection{Correlation analysis of the soil chemical properties}

Soil nutrient quality directly affects the direction of succession and the speed of vegetation communities in grassland mining areas. ${ }^{27,28}$ The main nutrient indicators, such as SOM, STN, SAP, and SAK, are both independent and interdependent, and they have a close relationship with the soil $\mathrm{pH}$ value. Therefore, we analyzed the correlations of the soil chemical properties (Table 4), which provided recommendations for improving soil $\mathrm{pH}$ and for rational fertilization.

Except for $\mathrm{pH}$, in the undamaged land, there are positive correlations between the soil nutrient indicators. However, the correlations between most indicators are not significant $(P>$ 0.05). The correlation between SOM and STN was significant and positive $(P<0.01)$, with a correlation coefficient of $R=0.97$. There was a significant positive correlation between SAP and SAK $(P<0.05)$, and the correlation coefficient was $R=0.91$. However, the correlations between the soil $\mathrm{pH}$ and the soil

Table 4 Correlation analysis of the soil chemical properties of the various plots ${ }^{a}$

\begin{tabular}{lllllll}
\hline Sample plot & Index & SOM & STN & SAP & SAK & pH \\
\hline Undamaged land & SOM & 1.00 & & & & \\
& STN & $0.97^{a}$ & 1.00 & & & \\
& SAP & 0.41 & 0.23 & 1.00 & & \\
South dump & SAK & 0.50 & 0.30 & $0.91^{a}$ & 1.00 & \\
& pH & -0.11 & -0.16 & 0.16 & 0.15 & 1.00 \\
& SOM & 1.00 & & & & \\
STN & $0.76^{a}$ & 1.00 & & & \\
North dump & SAP & -0.11 & -0.10 & 1.00 & & \\
& SAK & $0.78^{a}$ & $0.71^{b}$ & 0.08 & 1.00 & \\
& pH & -0.29 & -0.55 & -0.45 & -0.35 & 1.00 \\
& SOM & 1.00 & & & & \\
& STN & $0.67^{b}$ & 1.00 & & & \\
& SAP & 0.26 & 0.22 & 1.00 & & \\
& SAK & 0.51 & $0.72^{a}$ & 0.13 & 1.00 & \\
& pH & $-0.86^{a}$ & -0.42 & -0.02 & -0.32 & 1.00
\end{tabular}

${ }^{a}$ At the 0.01 level (two-tailed), the correlation is significant. ${ }^{b}$ At the 0.05 level (two-tailed), the correlation is significant. nutrient indicators were very weak or non-existent $(-0.02<R<$ 0.02). For the south dump, there were significant positive correlations between SOM and STN and SAK, with correlation coefficients of 0.76 and 0.78 , respectively. There was a significant positive correlation between STN and SAK, and the correlation coefficient was $R=0.71$. In addition, the correlation between SAP and the other soil nutrient indicators was weak or non-existent $(-0.02<R<0.02)$, and the negative correlations between the soil $\mathrm{pH}$ and the soil nutrient indicators were not significant. For the north dump, there were positive correlations between the soil nutrient indicators. There was a significant positive correlation between SOM and STN, and a significant negative correlation with the soil $\mathrm{pH}$ value, with correlation coefficients of 0.67 and -0.86 , respectively. There was a significant positive correlation between STN and SAK, and the correlation coefficient was $R=0.72$. In addition, the correlations between the other indicators in the sample were not significant.

The above analysis revealed that in the damaged land formed by mining following reclamation, the correlation between SOM and STN was weaker than that in the undamaged land, whereas the correlation between STN and SAK was significantly stronger than that in the undamaged land.

The correlations between the soil chemical properties were analyzed (Table 5) in the vertical section. In the $0-10 \mathrm{~cm}$ soil layer, there were significant $(P<0.05)$ positive correlations between the soil nutrient indicators. There were extremely significant positive correlations between SOM and STN and SAK $(P<0.01)$, and a significant positive correlation between SOM and SAP, with correlation coefficients of $0.90,0.88$, and 0.69 , respectively. There were significant positive correlations between STN and SAP and SAK, with correlation coefficients of 0.75 and 0.68 , respectively. SAP was significantly and positively correlated with SAK, and the correlation coefficient was $R=$

Table 5 Correlation analysis between the soil chemical properties in the different soil layers of the various plots

\begin{tabular}{lllllll}
\hline Soil depth (cm) & Index & SOM & STN & SAP & SAK & pH \\
\hline $0-10$ & SOM & 1.00 & & & & \\
& STN & $0.90^{* *}$ & 1.00 & & & \\
& SAP & $0.69^{*}$ & $0.75^{*}$ & 1.00 & & \\
& SAK & $0.88^{* *}$ & $0.68^{*}$ & $0.73^{*}$ & 1.00 & \\
pH & $-0.67^{*}$ & -0.50 & -0.48 & $-0.72^{*}$ & 1.00 \\
$10-20$ & SOM & 1.00 & & & & \\
& STN & $0.71^{*}$ & 1.00 & & & \\
& SAP & 0.44 & 0.09 & 1.00 & & \\
$20-30$ & SAK & 0.17 & 0.00 & 0.28 & 1.00 & \\
& pH & $-0.73^{*}$ & -0.42 & -0.44 & -0.30 & 1.00 \\
& SOM & 1.00 & & & & \\
& STN & 0.65 & 1.00 & & & \\
& SAP & 0.05 & -0.23 & 1.00 & & \\
& SAK & $0.75^{*}$ & 0.00 & 0.35 & 1.00 & \\
& pH & $-0.80^{* *}$ & -0.66 & -0.11 & -0.54 & 1.00 \\
& SOM & 1.00 & & & & \\
& STN & 0.45 & 1.00 & & & \\
& SAP & 0.08 & -0.29 & 1.00 & & \\
& SAK & 0.55 & -0.26 & $0.74^{*}$ & 1.00 & \\
& pH & -0.38 & -0.57 & -0.49 & -0.42 & 1.00
\end{tabular}


Table 6 Explanation of total variance ${ }^{a}$

\begin{tabular}{|c|c|c|c|c|c|c|}
\hline Component & \multicolumn{3}{|c|}{ Initial eigenvalue } & \multicolumn{3}{|c|}{ Extract the sum of squares of loads } \\
\hline 2 & 1.088 & 21.760 & 75.274 & 1.088 & 21.760 & 75.274 \\
\hline 3 & 0.526 & 10.519 & 85.793 & & & \\
\hline 4 & 0.476 & 9.523 & 95.316 & & & \\
\hline
\end{tabular}

${ }^{a}$ Extraction method: principal component analysis. Extraction principle: when the eigenvalues $\geq 1$, it corresponds to the first " $n$ " principal components

0.73. The soil pH was significantly and negatively correlated with SOM and SAK. In the $10-20 \mathrm{~cm}$ soil layer, there were positive correlations between the soil nutrient indicators. However, a significant positive correlation was found only between SOM and STN, with a correlation coefficient of $R=0.71$, and the positive correlations between the other indicators were not significant $(P>0.05)$. The soil $\mathrm{pH}$ was significantly and negatively correlated with SOM, and the correlation coefficient was $R=$ -0.73 . In the $20-30 \mathrm{~cm}$ soil layer, there were positive correlations between the soil nutrient indicators, but a significant positive correlation was found only between SOM and SAK, with a correlation coefficient of $R=0.75$; the correlations between the other soil nutrient indicators were not significant $(P>0.05)$. The correlations between the soil $\mathrm{pH}$ and the soil nutrients were similar to those observed in the $10-20 \mathrm{~cm}$ layer. In the $30-40 \mathrm{~cm}$ soil layer, there was a significant positive correlation between SAP and SAK $(P<0.05)$, but the correlations between the other soil chemical properties were not significant $(P>0.05)$.

In the $0-40 \mathrm{~cm}$ soil layers, there were significant or highly significant positive correlations between SOM and the other nutrient indicators, and negative correlations with the soil $\mathrm{pH}$, indicating that SOM is the core element associated with the chemical transformation of soil. With an increase in soil depth, the correlations between the soil chemical properties tend to decline sharply.

\subsection{Comprehensive evaluation of the soil chemical properties}

As the levels and rankings of SOM, STN, SAP, SAK, and $\mathrm{pH}$ in the undamaged and reclaimed lands differed, a single chemical indicator can only reflect a certain aspect of the soil quality,

Table 7 Initial factor load matrix ${ }^{a}$

\begin{tabular}{lll}
\hline & \multicolumn{2}{l}{ Component } \\
\cline { 2 - 3 } Index & 1 & 2 \\
\hline SOM & 0.872 & -0.223 \\
STN & 0.737 & -0.422 \\
SAP & 0.564 & 0.687 \\
SAK & 0.708 & 0.522 \\
pH & -0.744 & 0.339
\end{tabular}

${ }^{a}$ Two components were extracted. therefore principal component analysis should be used to comprehensively evaluate the soil chemical status in mining areas. ${ }^{24,29,30}$ We used SPSS 25.0 to analyze the above-mentioned soil chemical properties. Through the pre-selection of variables, two principal component variables were selected in this study (Table 6), and the contribution to variance was 53.14 and $21.76 \%$, respectively. The cumulative contribution rate was $75.27 \%$, indicating $75.27 \%$ information from each test sample, and a $24.73 \%$ loss of information. Table 7 shows that SOM, STN, $\mathrm{SAK}$, and $\mathrm{pH}$ have higher loads on the first principal component, indicating that this component reflects the information on SOM, STN, SAK, and pH. Conversely, SAP had a higher load on the second principal component, indicating that this component reflects information on SAP.

Based on (1), the corresponding coefficients of the respective indicators of the principal components are shown in Table 8 . The coefficients are substituted into (2) and (3) to obtain the $F_{1}$ and $F_{2}$ values of the principal components 1 and 2, and the comprehensive scores ( $F$ value) of the indicators are subsequently calculated using (4).

$$
\begin{gathered}
U_{i}=\frac{A_{i}}{\sqrt{\lambda_{i}}} \\
F_{1}=0.533 Z_{1}+0.451 \mathrm{ZX}_{2}+0.345 Z \mathrm{ZX}_{3} \\
+0.433 \mathrm{ZX}_{4}-0.455 \mathrm{ZX} \\
F_{2}=-0.214 \mathrm{ZX}_{1}-0.405 \mathrm{ZX}_{2}+0.659 \mathrm{ZX} 3 \\
+0.500 \mathrm{ZX}_{4}-0.325 \mathrm{ZX}_{5} \\
F=\frac{F_{1} \lambda_{1}+F_{2} \lambda_{2}}{\lambda_{1}+\lambda_{2}}
\end{gathered}
$$

Table 8 Principal component load matrix ${ }^{a}$

\begin{tabular}{lll}
\hline & \multicolumn{2}{l}{ Component } \\
\cline { 2 - 3 } Index & 1 & 2 \\
\hline SOM & 0.533 & -0.214 \\
STN & 0.451 & -0.405 \\
SAP & 0.345 & 0.659 \\
SAK & 0.433 & 0.500 \\
pH & -0.455 & 0.325 \\
${ }^{a}$ Two components were extracted. &
\end{tabular}


Table 9 Comprehensive scores and rankings of the principal components of the soil chemical properties in the various plots ${ }^{a}$

\begin{tabular}{llll}
\hline & $\begin{array}{l}\text { Principal component } \\
\text { 1 score }\end{array}$ & $\begin{array}{l}\text { Principal component } \\
\text { 2 score }\end{array}$ & \multicolumn{2}{c}{$\begin{array}{l}\text { Comprehensive } \\
\text { score }\end{array}$} \\
\hline Undamaged land & 0.907 & -0.667 & 0.453 \\
South dump & -1.363 & 0.143 & -0.927 \\
North dump & 0.453 & 0.524 & 0.475 \\
a & & 3 \\
${ }^{2}$ Data in the table are the average of twelve replicates. & & 1
\end{tabular}

Table 10 Comprehensive scores and rankings of the soil chemical properties in the different soil layers of the studied mining area ${ }^{a}$

\begin{tabular}{lllcr}
\hline Soil depth $(\mathrm{cm})$ & Undamaged land & South dump & North dump & $\begin{array}{l}\text { Comprehensive } \\
\text { score }\end{array}$ \\
\hline $0-10$ & 1.897 & -0.614 & 1.225 & 0.836 \\
$10-20$ & 0.570 & -1.240 & 0.155 & -0.172 \\
$20-30$ & -0.115 & -1.274 & 0.367 & -0.340 \\
$30-40$ & -0.542 & -0.581 & 0.153 & -0.323
\end{tabular}

${ }^{a}$ Data in the table are the average of three replicates.

where $U_{i}$ represents the principal component load matrix, $A_{i}$ represents the initial factor load matrix, and $\lambda_{i}$ represents its corresponding eigenvalue. $\mathrm{ZX}_{1}, \mathrm{ZX}_{2}, \mathrm{ZX}_{3}, \mathrm{ZX}_{4}$, and $\mathrm{ZX}_{5}$ are values normalized by the original variables, including SOM, STN, SAP, SAK, and the soil pH value. $F$ is the comprehensive score, $F_{1}$ and $F_{2}$ are the scores of the main components 1 and 2, respectively, and $\lambda_{1}$ and $\lambda_{2}$ are the main components 1 and 2 , respectively corresponding to the eigenvalues.

Based on the above calculations, we obtained the main component scores, and the comprehensive scores of the soil chemical properties in the different regions are shown in Table 9. We found that the higher the comprehensive score, the better the soil chemical properties. The results show that the soil chemical properties in the north dump after 8 years of reclamation are the best, with a comprehensive score of 0.48 , followed by those of the undamaged land, with a comprehensive score of 0.45 . Finally, the soil chemical properties in the south dump after 4 years of reclamation were the worst, with a comprehensive score of -0.93 . Therefore, the chemical properties of the reconstructed soil improved as the number of reclamation years increased.

The results of the principal component analysis (Table 10) revealed that the comprehensive scores of the soil chemical properties in the $\mathbf{0}-\mathbf{1 0} \mathrm{cm}$ soil layer were the highest, followed by those in the 10-20, 30-40, and 20-30 cm layers, at $0.84,0.17$, -0.32 , and -0.34 , respectively. This indicated that the values for the chemical properties of the soil decreased with an increase in soil depth; the nutrient status of the surface soil was better than that of the other soil layers, and the comprehensive chemical properties of the soils below $20 \mathrm{~cm}$ were very similar.

\section{Discussion}

\subsection{Effects of mining and reclamation on the soil chemical properties}

Opencast coal mining activities severely damage the original geological formations, causing inevitable damage to the soil and vegetation..$^{31}$ In order to analyze the chemical properties and differentiation mechanisms of the reconstructed soils, we have reviewed the literature. Jobbágy et al. ${ }^{32}$ believe that the SOM content in the topsoil is higher than that in the deep layer, whether it is reclaimed or undamaged, which may be related to the conversion of the surface soil litter to humic acid. In general, except for a few prokaryotes, animals and plants can not directly use inorganic nitrogen in soil and oceans. Nitrogen conservation and effective circulation are essential for maintaining ecosystem productivity, ${ }^{33}$ but opencast coal mining reduces STN content. Bronick et $a l .{ }^{34}$ found that land reclamation activities can help increase the proportion of reconstructed soil aggregates, thereby reducing soil nutrient loss caused by rainfall and irrigation, which may be one of the reasons why the SAP and SAK levels in the reconstructed soil increased relative to those in natural soil. The SAP and SAK levels in the undamaged land were lower, probably due to the absorption and assimilation of $\mathrm{P}$ and $\mathrm{K}$ elements in the plant roots during ecosystem reconstruction. Related studies have shown that $\mathrm{pH}$ can regulate the availability of plant nutrients and can play an important role in plant recovery, but the soil disturbance caused by mining seriously impacts the soil $\mathrm{pH}$ value, and bedrock and carbonate mulch promote an increase in soil $\mathrm{pH} .{ }^{\mathbf{1 1 2 , 3 5}}$

\subsection{Influence of reclamation years on the soil chemical properties}

Reclamation years are important for measuring soil quality following reclamation. We found that the impact of mining on the chemical properties of the reconstructed soil in the grassland mining area was similar to that in other opencast mines, but a difference existed when considering reclamation years. $\mathrm{Li}^{36}$ and Wang et $a{ }^{37}$ believe that the SOM and STN levels decrease after mining, and that it takes decades for them to recover to near natural levels. In the present study, there was no significant difference in the SOM content between the 
undamaged land and the north dump after 8 years of reclamation, but a significant difference was still found for STN content. The SOM and STN levels in the south dump after 4 years of reclamation were lower than those in the north dump. In addition, the SAP and SAK levels in the north dump were higher than those in the undamaged land, as reported by Cao et $a .^{12}$ and Banning et al. ${ }^{38}$ As the number of reclamation years increases, the amount of $\mathrm{P}$ and $\mathrm{K}$ available for direct use by plants increases. Regarding $\mathrm{pH}$, the $\mathrm{pH}$ in the south dump was higher than that in the north dump and the undamaged land. In general, the soil chemical properties in the south dump after 4 years of reclamation were significantly different from those in the undamaged land, and the differences between the north dump after 8 years of reclamation and the undamaged land were small. Therefore, the number reclamation years is an important factor affecting the quality of land reclamation.

\subsection{Improvements in the chemical properties of reconstructed soil}

Based on nutrient grading, we found that the soil nutrient status of the undamaged land and the north dump was better than that of the south dump. $\mathrm{Shi}^{\mathbf{2 4}}$ reported that the SAP content in grassland mining areas is generally lacking. Opencast mining activities lead to a substantial loss of soil nutrients, ${ }^{39}$ however, in the present study, the SAK content of the north dump after 8 years of reclamation exceeded that of the undamaged land, and was level 1. In addition, Cao et al. ${ }^{40}$ and Wang et al. ${ }^{20}$ reported significant or highly significant positive correlations between SOM and the other nutrient indicators. How to utilize the main role of SOM in nutrient conversion and circulatory systems is important for current reclamation work.

We used principal component analysis to comprehensively evaluate the soil chemical status of the mining area in the present study. The chemical property score of the soil in the north dump was 0.48 , the comprehensive score in the undamaged land was 0.45 , and the comprehensive score in the south dump was -0.93 . Therefore, as the number of reclamation years increased, the comprehensive status of the reconstructed soil chemical properties improved, ${ }^{41,42}$ which may be due to the different levels of coal gangue in the process of land reclamation. In the study area of the present analysis, coal gangue was contained in the soil layer below $20 \mathrm{~cm}$ in the north dump and below $40 \mathrm{~cm}$ in the south dump. With the weathering of coal gangue, the SOM content in the soil increases, ${ }^{20}$ leading to improvements in the chemical quality of the soil in the north dump compared with that in the south dump. Therefore, in grassland mining areas where topsoil is scarce, the weathering effect of coal gangue can be used to improve the soil chemical properties, such that the topsoil and coal gangue can be used to construct the soil profile.

In addition, the chemical properties of the soil in the 0 $10 \mathrm{~cm}$ soil layer were the most desirable, and the comprehensive score $F$ was 0.84 , which is significantly higher than those of the other soil layers. This is followed by the $10-20 \mathrm{~cm}$ soil layer $(F=$ $-0.17)$, the $20-30 \mathrm{~cm}$ layer $(F=-0.34)$, and the $30-40 \mathrm{~cm}$ layer $(F=-0.32)$. This shows that the chemical properties of the soil deteriorate with an increase in soil depth, and the comprehensive chemical properties of the $20-30$ and $30-40 \mathrm{~cm}$ soil layers are the most similar; this is consistent with the results reported by Sun et $a l^{43}$ and Sun et $a l^{44}$ As the number of reclamation years increases, the quality of the surface soil continues to improve, and the quality of the surface layer is higher than the lower layer.

\section{Conclusions}

Opencast mining destroys the chemical properties of natural soil; the chemical properties of the reconstructed soil profile gradually improve following land reclamation. The SAP and SAK levels in the north dump after 8 years of reclamation were higher than those in the undamaged land. The SOM and STN levels in the north dump were lower than those in the undamaged land, but the soil nutrient content in the south dump after 4 years of reclamation was lower than that in the undamaged land, while the $\mathrm{pH}$ in the south dump was higher than that in the undamaged land. Via principal component analysis, we found that the chemical properties of the soil improved as the number of reclamation years increased; the chemical quality of the soil improved, but the chemical quality of the soil gradually decreased with increasing soil thickness.

Improving the chemical quality of reconstructed soil in the reclaimed land is essential for rebuilding vegetation and ecological restoration. Using correlation analysis, we found that SOM is a core element that is important for the soil chemical properties in grassland opencast mining areas with scarce topsoil and arid climate. In the $0-40 \mathrm{~cm}$ soil layer, the correlations between the soil chemical properties gradually decrease from top to bottom, and gradually change from interdependent to mutually independent. Based on the above research, we found that the use of topsoil and coal gangue to layer the soil profile can effectively improve the chemical properties of the reconstructed soil profile.

\section{Conflicts of interest}

There are no conflicts to declare.

\section{Acknowledgements}

This research was supported by the Sub Project of the National Key Research Program of China (2016YFC0501105-2), National Natural Science Foundation of China $(41701607,41571508)$ and the Basic Scientific Research Foundation for Excellent Supervisors (2-9-2017-103). We thank Gubai Luo, Shufei Wang, and Geng Yang for their help with the field and laboratory work. We are extremely grateful to the anonymous reviewers for their insightful comments and suggestions.

\section{References}

1 H. Li, H. B. Shao, W. X. Li, R. Bi and Z. Bai, Clean-Soil, Air, Water, 2012, 40, 233-238. 
2 J. M. Wang, R. X. Yang and Z. K. Bai, Arabian J. Geosci., 2017, 10, 1-13.

3 Z. F. Bian, Resour. Ind., 2005, 7, 18-24.

4 D. Y. Huang, Hunan Nonferrous Met., 2011, 27, 45-48.

5 J. C. Li, Z. K. Bai, S. J. Chai, J. Y. Yue, H. Y. Wang and Y. H. Wang, Sci. Technol., 2009, 27, 30-34.

6 X. Y. Liu, Z. K. Bai, W. Zhou, Y. G. Cao and G. J. Zhang, Ecol. Eng., 2017, 98, 228-239.

7 Y. Rong, Z. Q. Hu, Y. H. Fu, D. M. Li, X. S. Wan and A. Waitkus, China Min. Mag., 2017, 26, 55-59.

8 Z. K. Bai, J. C. Li, W. Y. Wang, X. Q. Ding, S. J. Chai, J. J. Chen, C. E. Lu and J. K. Zhao, China Land Sci., 2000, 14, 1-4.

9 D. E. Lewis, J. R. White, D. Wafula, R. Athar, T. Dickerson, H. N. Williams and A. Chauhan, Microb. Ecol., 2010, 59, 710-723.

10 V. A. Akala and R. Lal, J. Environ. Qual., 2001, 30, 2098-2104. 11 J. M. Wang, R. X. Yang and Z. K. Bai, Trans. Chin. Soc. Agric. Eng., 2012, 28, 229-235.

12 Y. G. Cao, Z. K. Bai, G. J. Zhang, W. Zhou, J. M. Wang, Q. F. Yu and Z. Z. Du, J. Agro-Environ. Sci., 2013, 32, 24222428.

13 C. Farnden, R. J. Vassov, M. Yarmuch and B. C. Larson, New Forests, 2013, 44, 799-810.

14 M. K. Shukla, R. Lal and D. Vanleeuwen, Soil Sci. Soc. Am. J., 2017, 71, 1748-1757.

15 Y. G. Cao, J. M. Wang, Z. K. Bai, W. Zhou, Z. Q. Zhao, X. Ding and Y. N. Li, Environ. Earth Sci., 2015, 74, 6367-6380.

16 Y. G. Cao, W. Zhou, Z. K. Bai, J. M. Wang and X. R. Zhang, Fresenius Environ. Bull., 2016, 25, 2331-2342.

17 M. K. Shukla, R. Lal, J. Underwood and M. Ebinger, Soil Sci. Soc. Am. J., 2004, 68, 1352-1359.

18 M. A. Naeth, D. S. Chanasyk and T. D. Burgers, Phys. Chem. Earth, 2010, 36, 19-30.

19 J. Vymazal and P. Sklenicka, Ecol. Eng., 2012, 43, 1-4.

20 J. M. Wang, H. D. Wang, Y. G. Cao, Z. K. Bai and Q. Qian, Sci. Rep., 2016, 6, 1523-1532.

21 X. Y. Liu, Y. G. Cao, Z. K. Bai, J. M. Wang and W. Zhou, Environ. Earth Sci., 2017, 76, 508-560.

$22 \mathrm{X}$. Ma, Ecological risk assessment of vulnerable mine area, China University of Geosciences, Beijing, 2011.
23 L. Zhu and F. C. Qin, Bull. Soil Water Conserv., 2008, 28, 111115.

24 J. G. Shi, Chin. Agric. Sci. Bull., 2013, 29, 157-161.

$25 \mathrm{~J}$. J. Pan, Investigation and Evaluation of soil resources, China Agricultural Press, Beijing, 2004, pp. 183-187.

26 W. Zhou, J. Wang, B. Zhang, L. Xiao, H. L. Lv and X. Y. He, Acta Ecol. Sin., 2017, 37, 1211-1220.

27 C. N. R. Critchley, B. J. Chambers and J. A. Fowbert, Biol. Conserv., 2002, 105, 199-215.

28 H. D. Wang, J. M. Wang, Y. G. Cao, Y. G. Lu, Q. Qin and Y. Wang, Acta Ecol. Sin., 2016, 36, 5098-5108.

29 Y. M. Zhao, J. S. Pan, R. Su, T. Zheng and J. J. Yang, Acta Agric. Boreali-Occident. Sin., 2014, 23, 210-216.

30 R. Yang, S. Liu, Z. Q. Wang, Y. C. Cao, Y. M. Zhao, W. X. He and Z. C. Geng, Acta Pedol. Sin., 2016, 53, 1037-1046.

31 R. K. Shrestha and R. Lal, Geoderma, 2010, 161, 168-176.

32 E. G. Jobbágy and R. B. Jackson, Ecol. Appl., 2000, 10, 423436.

33 D. L. Mummey, P. D. Stahl and J. S. Buyer, Soil Biol. Biochem., 2002, 34, 1717-1725.

34 C. J. Bronick and R. Lal, Geoderma, 2004, 124, 3-22.

35 Z. Q. Hu, J. Z. Qi and J. T. Si, J. China Coal Soc., 2002, 27, 639643.

36 M. S. Li, Sci. Total Environ., 2005, 357, 38-53.

37 J. M. Wang, R. X. Yang and Z. K. Bai, Ecol. Eng., 2015, 82, 159164.

38 N. C. Banning, B. M. Lalor and W. R. Cookson, Appl. Soil Ecol., 2012, 56, 27-34.

39 B. Z. Xin, X. X. Yu, M. L. Zhang, Q. Y. Li and H. G. Li, Arid Zone Res., 2012, 29, 379-384.

40 Y. G. Cao, Z. K. Bai, Z. Q. Zhao, G. J. Zhang, W. Zhou, J. M. Wang, M. Jing, X. Y. Song and J. Food, Agric. Environ., 2014, 12, 1045-1053.

41 N. M. Zhang, X. P. Wu, X. B. Gu and X. Y. Zhang, Chin. J. Soil Sci., 2003, 34, 58-60.

$42 \mathrm{~J} . \mathrm{H}$. Ma, The effect of vegetation reclamation on soil properties in Heidaigou mine dump, Northwest A \& F University, 2015.

43 T. S. Sun, X. Y. Shi, Y. M. Yang and F. H. Meng, J. Soil Water Conserv., 2003, 17, 35-37.

44 H. Y. Sun, X. J. Li, Z. Q. Hu, X. R. Liu and W. J. Zhong, Trans. Chin. Soc. Agric. Eng., 2008, 24, 205-209. 